\title{
Understanding the Mechanical Biases of Tipping-Bucket Rain Gauges: A Semi-Analytical Calibration Approach
}

\author{
Daniel A. Segovia-Cardozo ${ }^{1, * \mathbb{C}}$, Leonor Rodríguez-Sinobas ${ }^{1}$, Andrés Díez-Herrero ${ }^{2}{ }^{\mathbb{D}}$, Sergio Zubelzu ${ }^{1}$ \\ and Freddy Canales-Ide ${ }^{1}$ (D) \\ 1 Research Group Hydraulics for Irrigation, Department Ingeniería Agroforestal, E.T.S.I. Agronómica, \\ Alimentaria y Biosistemas, Universidad Politécnica de Madrid, Ciudad Universitaria s/n, \\ 28040 Madrid, Spain; leonor.rodriguez.sinobas@upm.es (L.R.-S.); sergio.zubelzu@upm.es (S.Z.); \\ freddy.canales.ide@alumnos.upm.es (F.C.-I.) \\ 2 Geological Hazards Division, Geological Survey of Spain, Instituto Geológico y Minero de España (IGME-CSIC), \\ Ríos Rosas 23, 28003 Madrid, Spain; andres.diez@igme.es \\ * Correspondence: da.segovia@upm.es; Tel.: +34-9-1336-5675
}

Citation: Segovia-Cardozo, D.A.; Rodríguez-Sinobas, L.; Díez-Herrero, A.; Zubelzu, S.; Canales-Ide, F. Understanding the Mechanical Biases of Tipping-Bucket Rain Gauges: A Semi-Analytical Calibration Approach. Water 2021, 13, 2285. https://doi.org/10.3390/w13162285

Academic Editor: Enedir Ghisi

Received: 29 June 2021

Accepted: 18 August 2021

Published: 21 August 2021

Publisher's Note: MDPI stays neutral with regard to jurisdictional claims in published maps and institutional affiliations.

Copyright: (c) 2021 by the authors. Licensee MDPI, Basel, Switzerland. This article is an open access article distributed under the terms and conditions of the Creative Commons Attribution (CC BY) license (https:/ / creativecommons.org/licenses/by/ $4.0 /)$.

\begin{abstract}
Tipping bucket rain gauges (TBR) are widely used worldwide because they are simple, cheap, and have low-energy consumption. However, their main disadvantage lies in measurement errors, such as those caused by rainfall intensity (RI) variation, which results in data underestimation, especially during extreme rainfall events. This work aims to understand these types of errors, identifying some of their causes through an analysis of water behavior and its effect on the TBR mechanism when RI increases. The mechanical biases of TBR effects on data were studied using 13 years of data measured at 10 TBRs in a mountain basin, and two semi-analytical approaches based on the TBR mechanism response to RI have been proposed, validated in the laboratory, and contrasted with a simple linear regression dynamic calibration and a static calibration through a root-mean-square error analysis in two different TBR models. Two main sources of underestimation were identified: one due to the cumulative surplus during the tipping movement and the other due to the surplus water contributed by the critical drop. Moreover, a random variation, not related to RI, was also observed, and three regions in the calibration curve were identified. Proposed calibration methods have proved to be an efficient alternative for TBR calibration, reducing data error by more than $50 \%$ in contrast with traditional static calibration.
\end{abstract}

Keywords: rain gauge; undercatchment; precipitation; rainfall measurement error

\section{Introduction}

An interest among humans in measuring precipitation started in ancient times since this atmospheric process is an important factor in the water cycle and in life, as it has a significant role in hydrological processes [1]. The earliest reference to a rain gauge was in India, in the fourth century before Christ [2]. Nowadays, there are many of different types of gauges used to monitor precipitation, among which TBRs are the most widely used worldwide. Rainfall data are important in various human activities, such as irrigation management, hydrological monitoring, water resource management, flood prevention, flood alert systems, runoff models, the calibration of distributed precipitation measurements, flow early warning systems [3-7], the downscaling of remote sensing precipitation models [8,9], radar calibration-validation [10-13], basin water balance and flood models [14], structure design and profitability in different projects (hydroelectric generation, dam, irrigation, city planning, etc.) $[15,16]$, and other fields where accurate rainfall data with high frequency are needed to improve applications, especially in atmospheric and hydrological management and forecasting.

Modern TBRs have evolved to become one of the most widely used rain gauges worldwide, employed by governmental agencies, airports, industries, farmers, and private 
individuals $[17,18]$ due to their simple manufacturing structure (based on an electric pulse, a magnet switch mechanism, and a counter), low cost of production, and energy saving (a key element for most of the manufacturing of weather instruments and automation) [19]. However, their main drawbacks are measurement error (which can be significant in heavy rainfall events or during light drizzle); losses from evaporation and wind effects [20-24]; onset time; the sampling procedure; inaccuracy in the determination of the bucket's rain residue and the stopping of precipitation [25]; maintenance problems (cleaning, colonization by insects or birds); and random errors [26].

In general, an underestimation of the total rainfall can be observed, which is caused by several factors, mainly RI and wind [27]. Underestimation errors can be significant for $\mathrm{RI}>25 \mathrm{~mm} \cdot \mathrm{h}^{-1}$ [18,19], and they increase nonlinearly as RI increases [17]. Modern TBR designs have made attempts to reduce these errors, modifying the bucket profile and/or using a siphon tube to deliver a pre-set volume of collected water to each bucket [28]. However, they have not avoided the errors even under optimum conditions, but have only minimized them $[19,29]$. Thus, calibration of TBRs is often needed to guarantee data quality. Rain gauge calibration is a complex interaction (many variables involved) of TBR characteristics, in which correction factors may change from season to season [19]. The most typical calibrations are static and dynamic calibrations.

Static calibration methods are recommended by manufacturers since they are the fastest and the easiest. This type of calibration is based on levelling the rain gauge and adjusting an adjustable stop crew, under the bucket, until a given water volume (added drop by drop with a nozzle) tips the bucket. This procedure is repeated several times until the tipping volume for each bucket fixes the tipping volume expected. This method assumes a constant water volume for tipping the bucket regardless of rainfall intensity. However, Humphrey et al. [17] has pointed out that it is not correct. The specific design and mechanical motion of TBR do not allow the buckets to reposition themselves fast enough after a tip to collect all the rainfall entering the outer funnel. Further, the measured bucket volume may vary regarding the water source (rainwater, tap water, etc.) or according to whether the buckets were initially dry or wet or even whether their surface was pre-treated [18].

Dynamic calibration is based on calibrating the TBR while the bucket is in motion [17]. It compares measured rain gauge rates with actual rainfall rates that have been calculated from applied flow rates, using the rain gauge diameter and the bucket volume. Several effective calibration methods have been proposed over the years: Calder and Kidd [30] suggested a method based on rain gauge parameters (bucket volume and the time between successive bucket tips); Niemczynowicz [29] proposed the equation $\mathrm{I}=\mathrm{aNb}$, where $\mathrm{I}$ is the measured rain gauge rate, $\mathrm{N}$ is the tipping rate, and $\mathrm{a}$ and $\mathrm{b}$ are fitting parameters. Marsalek [18] determined an analytical expression comparing the nominal rainfall depth increment per tip and the time required for filling the bucket; Humphrey et al. [17] described an automated system performing dynamic calibration; Costello and Williams [31] proposed a method considering a laboratory-determined calibration curve; Luyckx and Berlamont [32] developed an analytical calibration taking into account the relationship between the rain gauge resolution and the slope of its regression line; Shedekar et al. [33] developed a linear regression and two dynamic calibration techniques; Shimizu et al. [34] developed a generalized correction equation for various TBRs; Sypka [35] developed an algorithm to implement a real-time dynamic volumetric correction based on a "tip interval" and nominal tip volume; Kohfahl and Saaltink [36] compared TBR measurements with a precision lysimeter and a weighing rain gauge. Alternatively, other authors have proposed different calibration methods [14,22,37-46].

Within this framework, this paper aims at understanding the development of the tipping bucket's mechanical biases in rain gauges related to RI, identifying its causes, and analyzing not only the behavior of water inside the rain gauge, but also its effects on precipitation measurement, which is accomplished by a semi-analytical approach of TBR functioning, so as to develop, apply, and validate alternative calibration methods to reduce 
the effects of mechanical biases on TBRs measurements and also to suggest possible changes in instrument design and to allow the design of a compensatory processing algorithm.

\section{Materials and Methods}

\subsection{Tipping Bucket Rain Gauge Characteristics}

Two rain gauge models from the same manufacturer (Davis Instruments, Hayward, CA, USA) were studied: Rain Collector II (RC1) and Rain Collector 7852M (RC2). Both, according to the manufacturer, present some similarities such as: $0.2 \mathrm{~mm}$ resolution $(D t)$, $\pm 4 \%$ accuracy up to $50 \mathrm{~mm} \cdot \mathrm{h}^{-1}$ and $\pm 5 \%$ from 50 to $100 \mathrm{~mm} \cdot \mathrm{h}^{-1}$, the same funnel orifice cross sectional area $\left(A, 0.1963 \mathrm{~cm}^{2}\right)$, and bucket height $(h b=0.0235$ and $0.023 \mathrm{~m})$. However, the main differences between them are the bucket volume $V t=4.245(\mathrm{RC} 1)$ and $4.28 \mathrm{~mL}$ (RC2), collection area $\Omega=212.27$ (RC1) and $214 \mathrm{~cm}^{2}$ (RC2), and specifically the linear distance travelled by the bucket during tipping time $h t=0.0385$ (RC1) and $0.0575 \mathrm{~m}$ (RC2) $[47,48]$.

The TBRs studied include the following components: the receiver; the tipping-bucket assembly, with circuitry for generating an output signal; and a recorder. The receiver is a funnel that collects rainwater towards the bucket, which is one half of a two-bucket receptacle, pivoted on a cylindrical axis. Once the upper bucket fills up to a specified water amount, the balance tips and the lower bucket moves into a position under the spout, where it carries out the emptying. The bucket's tipping is set by two calibration stop screws (one for each bucket). Each bucket's tip generates an electric pulse through a magnetic reed switch to the recorder, and each pulse is set as a nominal amount of rainfall according to the fixed tipping volume [18].

\subsection{Rain Gauge Calibration}

The two rain gauge models were calibrated with four different methods: a typical static calibration (suggested by the rain gauge manufacturer), a dynamic calibration, a semi-analytic calibration, and a simplified version of the latter. Seventy-eight different RI values from 0 to $900 \mathrm{~mm} \cdot \mathrm{h}^{-1}$ were used for calibration, and the results of each method were applied over the measured values obtained by the gauge without calibration, as well as contrasted with their equivalent rainfall depth applied during each test (onwards "real values") through a root-mean-square error analysis (RMSE).

\subsubsection{Static and Dynamic Calibrations}

Calibrations were performed under laboratory conditions. At first, static calibration was achieved, following the recommendations of the manufacturer and Humphrey et al. [17] by adding water drop by drop to fix a $0.2 \mathrm{~mm}$ per tip resolution for each bucket. Then, the dynamic calibration was carried out considering a simple nonlinear regression model between the measured rainfall depth per tip and the gauge-measured RI values, as a mean of the 1-min time measurements used during each test, based on the UNE EN 17277:2021 Standard, although it did not follow the recommendations about the duration of the total test.

A constant-head siphon connected to a nozzle, similar to that used by Sypka [35], was used to maintain a permanent flow rate during the dynamic calibration. The flow rate was calculated by the applied water volume, measured by a precision laboratory balance $\left( \pm 0.1 \mathrm{~g}\right.$ resolution, assuming $1 \mathrm{~g} \approx 1 \mathrm{~cm}^{3}$ ) each minute, measured with a $\pm 0.02 \mathrm{~s}$ resolution clock, in a custom-made data logger. The flow rate of each test was regulated by a globe valve.

For each TBR model, 33 and 45 experimental tests were performed in RC1 and RC2, respectively, for dynamic calibration at different RIs from $32 \mathrm{~mm} \cdot \mathrm{h}^{-1}$ to $900 \mathrm{~mm} \cdot \mathrm{h}^{-1}$. The durations of the tests were 20 and $10 \mathrm{~min}$ for $\mathrm{RI}<100 \mathrm{~mm} \cdot \mathrm{h}^{-1}$ and $\mathrm{RI}>100 \mathrm{~mm} \cdot \mathrm{h}^{-1}$, respectively.

\subsubsection{Semi-Analytical Calibration}

This study proposes a semi-analytical method that considers TBR behavior, and it determines some of the key variables focusing on both physical principles and experimental 
procedures. The method requires some initial information about rain gauge characteristics (Figure 1), as described in the section below; these were either obtained from the manufacturer's brochure, determined by experimental methods, or measured with an electronic Vernier caliper gauge $(0.01 \mathrm{~mm}$ resolution).

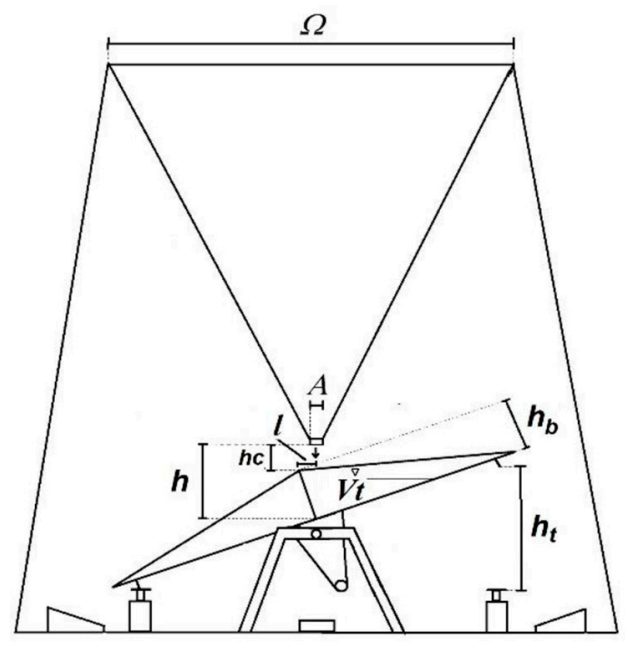

Figure 1. Tipping bucket rain gauge diagram.

Rainfall intensity data increased as different size steps from 0 to $950 \mathrm{~mm} \cdot \mathrm{h}^{-1}$ were used for simulation. As in the UNE EN 17277:2021 Standard, the flow rate $(Q)$ applied in the tests can be expressed as RI considering the funnel collection area of each rain gauge $(\Omega)$ and vice versa. Therefore, simulated RIs were expressed as $Q$. However, since at low RI, water through the orifice discharges as drops [32], an experimental procedure was achieved to measure the average volume of water per drop and its variability as a function of RI, which was used to express $Q$ as drops. $\mathrm{s}^{-1}$ in order to estimate the time needed to form a drop (Tfd). Twenty tests were performed at different RIs, ranging from 5 to $200 \mathrm{~mm} \cdot \mathrm{h}^{-1}$. For each of them, the constant head siphon supplied $10 \mathrm{~mL}$ water through the nozzle to the levelled funnel; in addition, a slow-motion camera located under the funnel (960 fps, $1080 \mathrm{fps}$ resolution) recorded on video the drops falling through the funnel orifice. Then, the videos were analyzed, and drops were counted to estimate the mean drop volume.

If drops fall freely from the funnel to the bucket, once a proper droplet size is reached, the time that it would take for a drop to travel the distance between the funnel and the impact zone on the bucket $(h)$ can be calculated by Newtonian mechanics for free fall as:

$$
t_{d}=\sqrt{2 h / g},
$$

where $t_{d}$ is the drop falling time (s); $h$ is expressed in (m) and $g$ in $\left(\mathrm{m} \cdot \mathrm{s}^{-2}\right)$.

If $t_{d}>T f d$, more than one drop will be falling at the same time, which means that the distance travelled for the next falling drop $\left(h_{d+1}\right)$ during $t_{d}$ can be determined by Newtonian mechanics (Equation (2)), since the next falling drop time will be $t_{d}-T f d$.

$$
h_{d+1}=v_{0} \cdot\left(t_{d}-T f d\right)+\frac{1}{2} g \cdot\left(t_{d}-T f d\right)^{2},
$$

where $v_{0}$ is the initial velocity, which would be zero (free fall) as long as water from the funnel falls as droplets; once it falls as a constant trickle, this assumption is no longer valid, and $v_{0}$ can be estimated by the ratio between $Q$ and $A$ (assuming there are no flow losses in the funnel).

This distance could be larger, shorter, or even null over Tfd. Therefore, if $t_{d}<T f d \Rightarrow$ $h_{d+1}<0$, because there is not enough time for a drop to form during $t_{d}$; if $t_{d}=T f d \Rightarrow h_{d+1}=0$ means that the drop is just about to fall; and if $t_{d}>T f d \Rightarrow h_{d+1}>0$, the next drop is already 
falling once $d$ impacts the bucket and can become a surplus if it falls on the falling bucket. However, to become a surplus, falling water needs extra time to fall a distance where it will be collected by the bucket in movement once the tipping movement is started by the critical drop $(D)$.

The bucket's movement is circular, so the time it takes to move from its upper position to the stop screw, once a drop triggered its falling movement (tipping movement time; $t_{t}$ ), will be equal to the time needed to change from one bucket, below the line of droplet fall, to the other. Thus, the time needed to travel the linear distance between the base of the bucket (in an upper position) to the stop screw $\left(h_{t}\right)$ will be the same time needed to cover the linear distance separating the drops' impact points in both buckets. Furthermore, if a static calibration was correctly made to set the same $h_{t}$ in the buckets, the time in which they are below the droplet line $\left(t_{u}\right)$ or the extra time for the next falling drops to become a surplus will be equal to the time the bucket covers half of the linear distance $h_{t}$ (Equations (3) and (4) and Figure 1).

$$
t_{u}=\sqrt{h_{t} / a}
$$

where $a$ is the falling bucket uniform acceleration $\left(\mathrm{m} \cdot \mathrm{s}^{-2}\right)$ and $h_{t}(\mathrm{~m})$.

Assuming $v_{0}=0$ :

$$
a=\frac{2 h_{t}}{t_{t}^{2}} \Rightarrow t_{u}=t_{t} / \sqrt{2},
$$

The surplus during tipping movement $(S t)$ will start once any extra drop is collected by the bucket during the downward motion. For a drop to become a surplus, it needs to fall at least a distance to be located within the bucket movement trajectory (drop catch fall distance, $h c$ ). Thus, the time required by the drops to become a surplus ( $t s$ ) would be the sum of the critical drop $t_{d}$ and $t_{u}$ minus the time needed by the drops to fall $h c$ :

$$
t s=t_{d}+t_{u}-\sqrt{\frac{2\left(h-\sqrt{h_{b}^{2}-l^{2}}\right)}{g}}=\sqrt{\frac{t_{t}{ }^{2}}{2 h t}+\frac{2 \cdot \sqrt{h_{b}^{2}-l^{2}}}{g}},
$$

where $t_{d}$ and $t_{u}(\mathrm{~s}), h(\mathrm{~m}), h_{b}$ is the bucket height $(\mathrm{m}), l$ is the linear distance from the middle point of the buckets to the droplet impact zone $(\mathrm{m})$, and $g\left(\mathrm{~m} \cdot \mathrm{s}^{-2}\right.$; Figure 1$)$.

Any drop originating during ts is regarded as surplus; a staggered increment in surplus as a function of RI must be expected since drops only fall in an integer number. $S t$ can be calculated by multiplying ts and $Q$ in drop $\cdot \mathrm{s}^{-1}$.

In addition to $S t$, there is another source of surplus caused by the $D$ size variation $(S d)$. Assuming a static force equilibrium on the buckets, the moment of inertia would be just smaller than the equivalent to $0.2 \mathrm{~mm}$, and water from the funnel falls as whole drops (not in fractions); the water surplus caused by the $D$ size would be included as a drop fraction exceeding the value that breaks the bucket's equilibrium. Assuming a constant moment of inertia in the buckets, the number of drops needed to start the tipping movement $(n d t)$, as a function of RI, can be estimated with the drop volume $(V d)$. Consequently, $S d$ can be determined (Equation (6)), and the total surplus (S) will be the sum of $S t$ and $S d$ (Equation (7)).

$$
S d=V d(1+E(n d t)-n d t)
$$

where

$$
\begin{gathered}
E: R \rightarrow Z \\
E(x)=[x]=\min \{k \in Z \mid x \leq k\} \\
S=S t+S d,
\end{gathered}
$$

Then, the corrected rainfall depth increment per tip $\left(D t^{\prime}\right)$ can be calculated considering the accumulated surplus due to the rain gauge's own operating mechanism ( $S t$ and $S d$; Equation (8)). Since $S d$ is due to the $D$ size, Equation (7) will be valid within the RI interval, 
where water falls as drops once it becomes a trickle; $S d=0$ and $S$ will only depend on $S t$ (Equation (9)).

$$
D_{t}^{\prime}=\frac{(V t+S) \cdot D_{t}}{V t},
$$

where $V t$ is the nominal volume needed to tip the bucket.

$$
S=Q \cdot t s,
$$

where $Q\left(\mathrm{~mL} \cdot \mathrm{s}^{-1}\right)$ and $t \mathrm{~s}(\mathrm{~s})$.

\subsubsection{Simplified Method}

The increase in drop size and the reduction on Tfd and $S d$ at low RI will generate a staggered increase pattern in $D t^{\prime}$ as RI increases. This staggered pattern can be adjusted through a regression, as in this case by the application of Equation (9) for every RI value (even in the drop interval) to simplify the $D t^{\prime}$ calculation, regarding $S d$ as negligible. Therefore, one assumes a constant $D t^{\prime}$ increment caused by the $Q$ increment at low RI, and $D t^{\prime}$ for every RI can be determined with only one equation, simplifying the calibration procedure:

$$
D_{t}^{\prime}=\frac{\left(V t+\left(Q * \frac{\partial t_{t}}{\partial Q}\right)\right.}{V t} \cdot D_{t},
$$

where $\mathrm{RI}$ is expressed as a flow $(Q)$ in $\mathrm{mL} \cdot \mathrm{s}^{-1}$.

\subsubsection{Tipping Movement Characterization}

The procedure described in the above section requires $t_{t}$; therefore, two experiments were performed: the first experiment determined a "free fall" $t_{t}$ and comprised five tests for each rain gauge at low RI to avoid any interference caused by the kinetic energy from the successive drops, or constant trickle, on the tipping mechanism. This requires no extra drop impacts on the bucket in movement $\left(h_{d+1}<0\right)$ to remove the effect of $t_{t}$ on the extra kinetic energy. The tested RIs were below 40 and $20 \mathrm{~mm} \cdot \mathrm{h}^{-1}$ for RC1 and RC2 (threshold calculated to meet $h_{d+1}<0$ ), respectively; four repetitions were applied to each test (two for each bucket); thus, there were 20 measurements to determine the average $t_{t}$ for each rain gauge. Each test was recorded in a slow-motion video that was watched later frame by frame. The $t_{t}$ was measured with a $0.01 \mathrm{~s}$ resolution chronometer recorded in the videos, from when $D$ hit the bucket to when it reached the stop screw.

The second experiment followed the decreasing trend of $t_{t}$ as RI increased due to the kinetic energy provided by the impact of the successive extra drops (or trickle). For each TBR, 20 tests were performed within an RI interval from 7 to $478 \mathrm{~mm} \cdot \mathrm{h}^{-1}$ in RC1 and from 18 to $466 \mathrm{~mm} \cdot \mathrm{h}^{-1}$ in RC2 in four repetitions, resulting in 80 measured values of $t_{t}$ per rain gauge. Tests were recorded in a slow-motion video.

Once water falls as a constant trickle, it is difficult to define when the bucket starts to move, so the $t_{t}$ values were measured from the time we were able to observe it in the slow-motion video until the bucket impacted the stop screw. This approach guarantees the same error in all measurements. In this way, we can measure the slope of reduction in $t_{t}$ and transpose it to the $t_{t}$ obtained in the first experiment without the effect of the extra kinetic energy.

In both experiments, the RI measured by the gauge was used and water was poured with a nozzle (connected to the constant head syphon), whose diameter was the same as that of the funnel orifice, and it was placed at the same $h$ distance to reproduce as much as possible the real gauge conditions to reduce the uncertainty added by the nozzle, regarded as negligible. 


\subsection{Mechanical Biases under Real Field Conditions}

To highlight the effect that mechanical biases can achieve in real conditions, the studied calibration methods were applied to the "Venero Claro" mountain basin $\left(15.53 \mathrm{~km}^{2}\right)$, located at the eastern Sierra de Gredos in Central Spain (Figure 2), which is well known in international scientific literature, due to its torrential behaviour, in which topography, elevation, rugged relief, and north orientation characterize its climatic conditions, generating strong rainfall events and causing considerable runoff and flash floods [49].

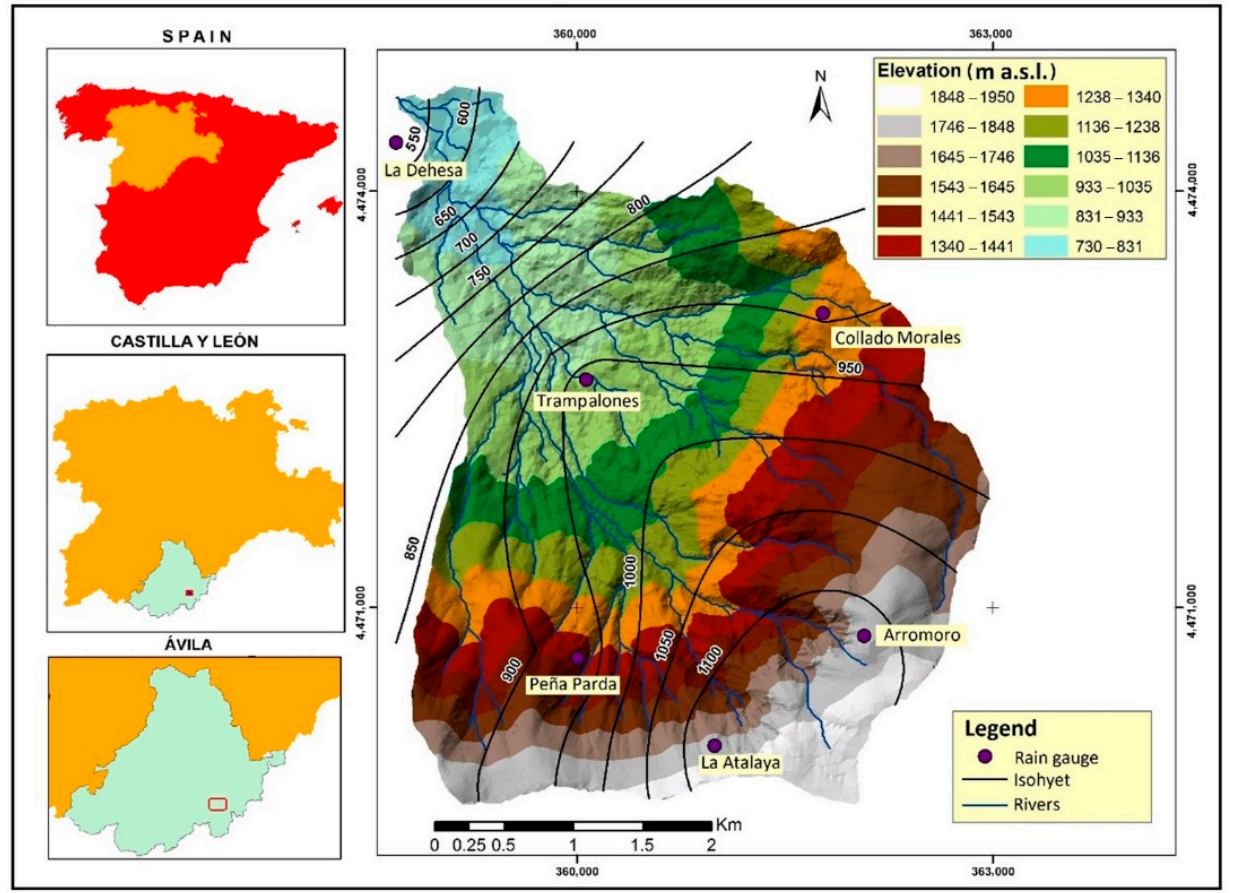

Figure 2. Location of the Venero Claro mountain basin and the TBR monitored places within the basin, elevation variation, and isohyets.

Since 2003, ten TBRs have been installed at six different locations across the basin (Figure 2): Arromoro (1831 m a.s.1.), Trampalones (920 m a.s.1.), Peña Parda (1420 m a.s.1.), La Atalaya (1790 m a.s.1.), Collado Morales (1287 m a.s.1.), and La Dehesa (736 m a.s.1.). The first rain gauge models installed were RC1. In October 2006, they were installed in La Atalaya and Peña Parda; in March of 2007 in Trampalones, Arromoro and Collado Morales; in February 2009, in La Dehesa. After 2016, new rain gauges (RC2) were installed in Peña Parda (2016), Arromoro (2017), and Collado Morales (2018). All of them were used in this study.

This paper studies all the recorded rain gauges data until 2019 from the six monitored areas, considering a 30-min average RI interval. Thus, the longest period (over 13 years) corresponded to La Atalaya and Peña Parda, and the shortest (11 years) to La Dehesa. For each area, the error was quantified, as a result of the application of the four methodologies described above, comparing the dynamic and semi-analytical calibration methods with the static calibration recommended by the manufacturer. The application of the methods in the basin assumes that the calibration curves for the two rain gauges models are valid for the TBR models located in the basin, which can generate some uncertainty. However, as they are not used for validation, we have considered that all data have the same uncertainty and are valid to understand the magnitude of the error under real conditions.

To characterize RI frequency and distribution along the basin, eight different RI intervals were studied: $10 \mathrm{~mm} \cdot \mathrm{h}^{-1}$ amplitude until $20 \mathrm{~mm} \cdot \mathrm{h}^{-1}, 20 \mathrm{~mm} \cdot \mathrm{h}^{-1}$ from 20 to $60 \mathrm{~mm} \cdot \mathrm{h}^{-1}, 40 \mathrm{~mm} \cdot \mathrm{h}^{-1}$ from 60 to $100 \mathrm{~mm} \cdot \mathrm{h}^{-1}$ and $50 \mathrm{~mm} \cdot \mathrm{h}^{-1}$ in the remainder. The first intervals were shorter since low RIs were more frequent. 


\section{Results}

\subsection{Dynamic Calibration}

Once the previous static calibration guaranteed the $D t$ onset (approximately at $0.2 \mathrm{~mm}$ in both buckets), the dynamic calibration curves were obtained (Figure 3). Data from both rain gauges were fitted to a second-order polynomial regression: $R C 2$ with $R^{2}=0.87$ and 0.74 for RC1. The $D t^{\prime}$ values were larger in RC2 (up to $0.3 \mathrm{~mm}$ per tip) than in RC1 (up to $0.242 \mathrm{~mm}$ ), probably due to the larger $h_{t}$, generating a longer $t_{t}$ and consequently a major surplus. Further, during the experiment storage in the funnel, it was possible to observe more than 540 and $620 \mathrm{~mm} \cdot \mathrm{h}^{-1}$ in RC1 and in RC2, respectively.

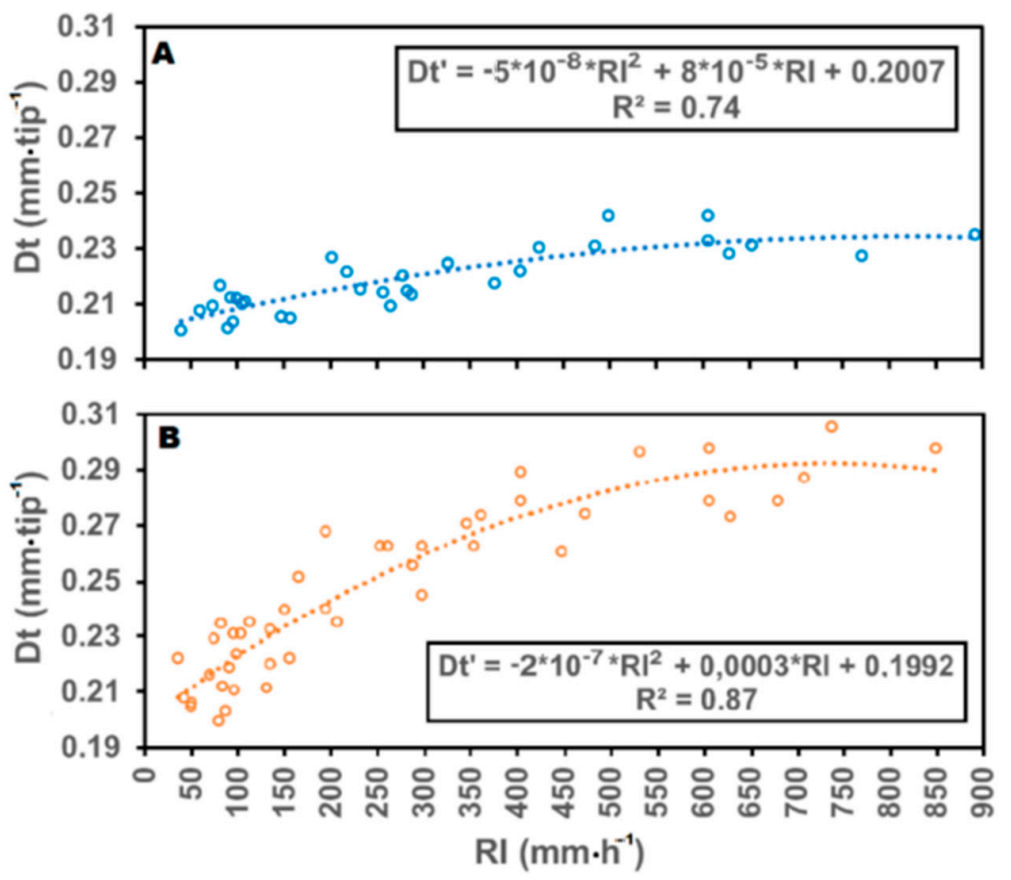

Figure 3. Non-linear regression obtained by dynamic calibration in laboratory tests. Variation of the rainfall depth per tip: (A) RC1 and (B) RC2. Each point represents a mean $D t$ value.

\subsection{Semi-Analytical Calibration}

\subsubsection{Drop Size}

In both rain gauges, drop size increased in a logarithmic pattern from 0 to $0.15 \mathrm{~mL}$ $\left(R^{2}=0.92\right)$ as RI increased (Figure 4) up to a threshold of between 200 and $210 \mathrm{~mm} \cdot \mathrm{h}^{-1}$, where the falling water changed from drops to trickle in both TBRs. This threshold was estimated from the slow-motion videos, as Figure 5 depicts.

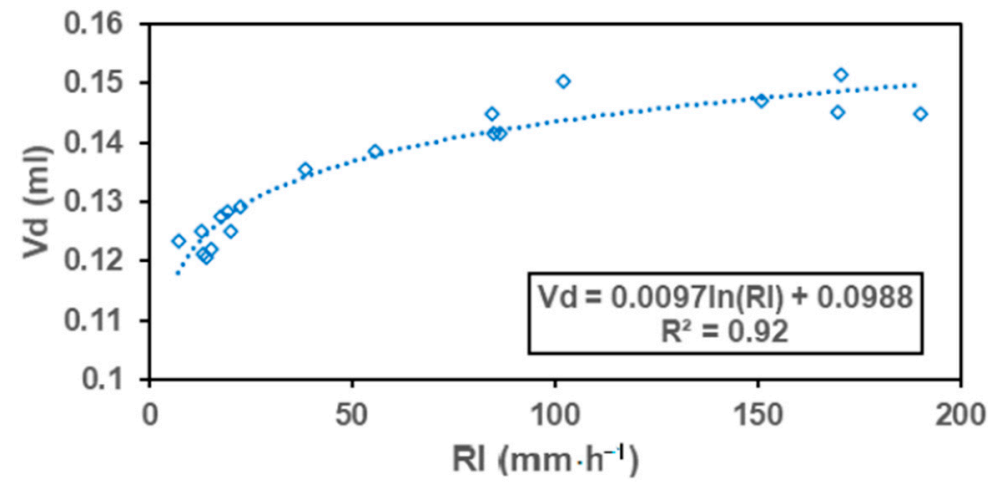

Figure 4. The drop size increment as a function of RI. 

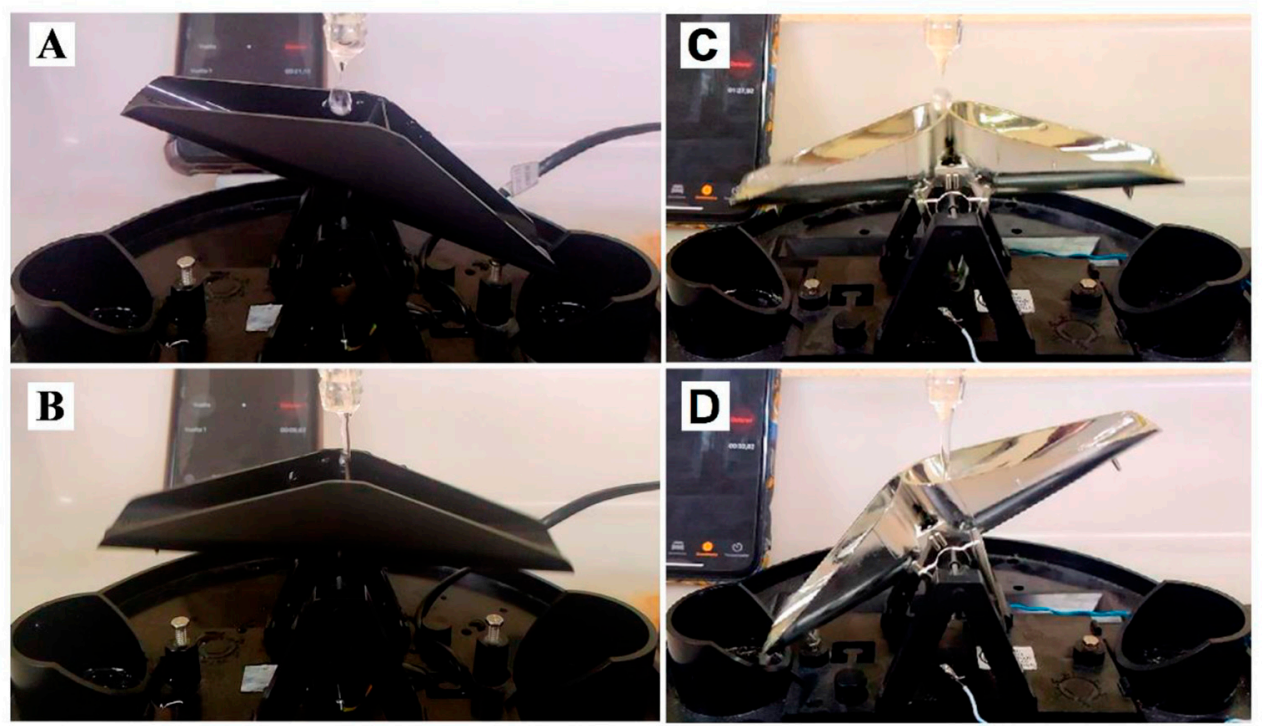

Figure 5. Example pictures of falling water behavior on the tipping mechanism: (A) a big drop at $198 \mathrm{~mm} \cdot \mathrm{h}^{-1} \mathrm{RI}(\mathrm{close}$ to becoming a constant trickle), falling on the static bucket of RC1; (B) constant trickle $\left(210 \mathrm{~mm} \cdot \mathrm{h}^{-1}\right)$ impacting only the division between buckets of RC1 during the tipping movement; (C) big drop (196 $\mathrm{mm} \cdot \mathrm{h}^{-1}$ ) falling in the middle of the buckets of RC2 during the tipping movement; and (D) a constant trickle $\left(215 \mathrm{~mm} \cdot \mathrm{h}^{-1}\right)$ falling on the bucket of RC2, while the other bucket spills water.

\subsubsection{Tipping Time}

The mean $t_{t}$ value for RC1 was lower than that for RC2, as was expected, since $h_{t}$ in $\mathrm{RC} 1(3.85 \mathrm{~cm})$ was shorter than in $\mathrm{RC} 2(5.75 \mathrm{~cm})$. The mean $t_{t}$ for $\mathrm{RC} 1$ was $0.68 \mathrm{~s}$, in a range of 0.44 with a standard deviation in which $\sigma=0.13$ and the $\mathrm{CV}=18.9 \%$, and in $\mathrm{RC} 2$, it was $1.1 \mathrm{~s}$, in a range of $0.65, \sigma=0.18$, and $\mathrm{CV}=16.17 \%$ (Figure 6).

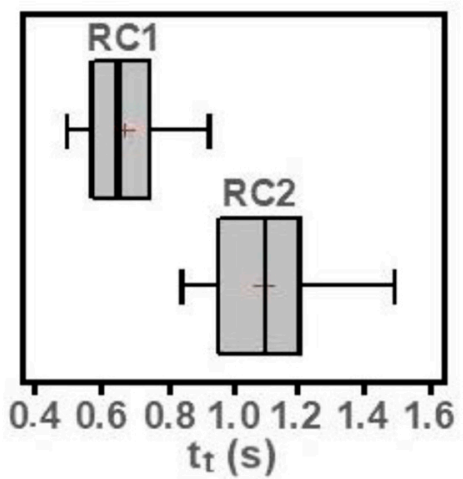

Figure 6. Box plot of the tipping time at low RI, where no extra drops fell during the tipping movement in both rain gauge models.

At low RI, the $t_{t}$ was expected to be constant, as suggested by the WMO [18,19,30], since the experimental tests prevented the kinetic energy effect of falling drops, but it was not. A random unexplained variation was observed, whose trend with RI was not noticeable.

On the other hand as was expected, a decreasing pattern was observed in $t_{t}$ when the kinetic energy of the impacting fluid increased as RI increased, which fit a decreasing linear regression with $\mathrm{R}^{2}=0.74$ and $\mathrm{R}^{2}=0.644$ for $\mathrm{RC} 1$ and $\mathrm{RC} 2$, respectively (Figure 7). Although the $\mathrm{R}^{2}$ coefficients were below 0.75 , their $t_{t}$ decreasing tendency was noticeable with a slope of -0.0005 in RC2 and -0.0003 in RC1, and $t_{t}$ showed an important reduction trend reaching an average of $40 \%$ at $480 \mathrm{~mm} \cdot \mathrm{h}^{-1}$ and $43 \%$ at $470 \mathrm{~mm} \cdot \mathrm{h}^{-1}$ for $\mathrm{RC} 1$ and $\mathrm{RC} 2$, respectively. The reduction in RC2 was larger due to its intrinsic characteristics, such as a 
more aerodynamic bucket and/or longer exposure time due to the effect of the falling fluid by virtue of its larger $t_{t}$.
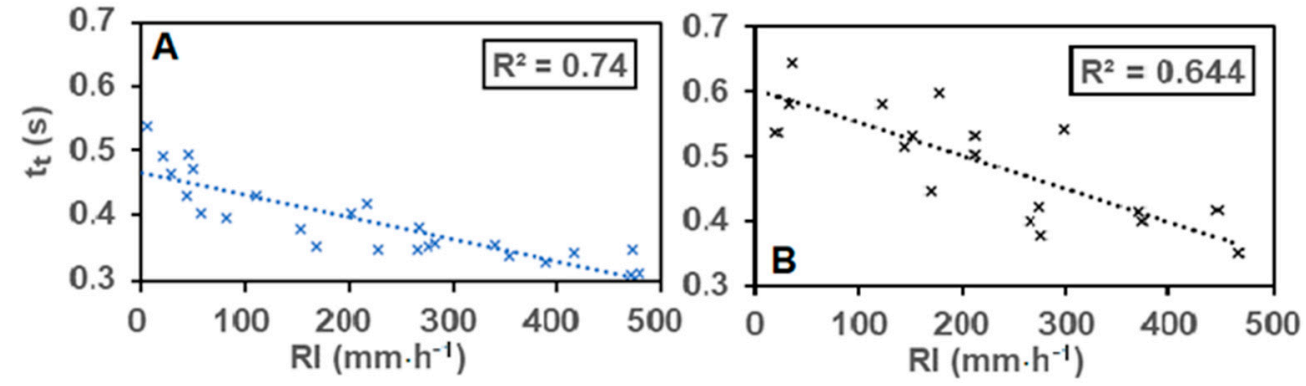

Figure 7. Tipping time reduction as RI increases. (A) Linear regression of RC1 and (B) RC2.

\subsubsection{Surplus Water}

The surplus water increases as RI increases [17,19] in a stepwise pattern of up to $200 \mathrm{~mm} \cdot \mathrm{h}^{-1}$ (Figure 8). Up to three drops in RC1 and five drops in RC2 can be accumulated as $S t$ during $t_{t}$ at $\mathrm{RI}<200 \mathrm{~mm} \cdot \mathrm{h}^{-1}$ (higher intensities produce a constant trickle).

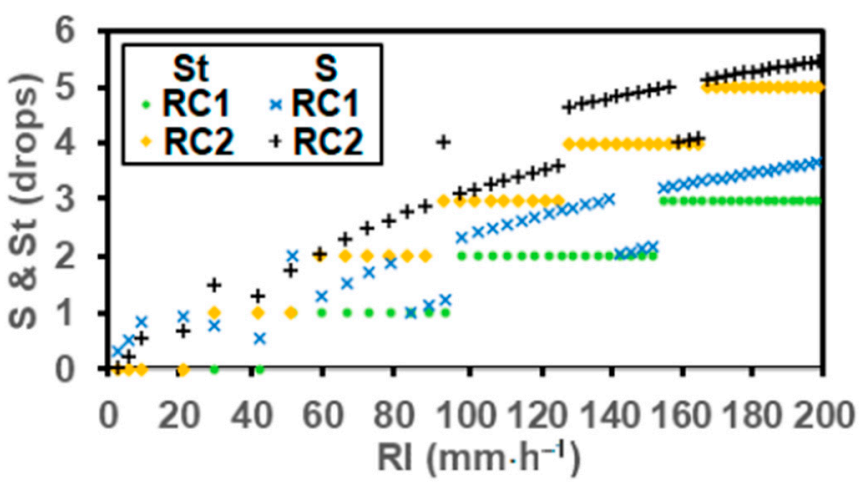

Figure 8. The relationship of the surplus water increment and RI in number of drops at RI under $200 \mathrm{~mm} \cdot \mathrm{h}^{-1}$. Staggered surplus increment during tipping movement and the total surplus amount.

The resulting $t_{d}$ values were $0.07280 \mathrm{~s}$ and $0.07350 \mathrm{~s}$ for RC1 and RC2, respectively. The larger value corresponds to RC2 due to its larger $h$. These values will remain almost constant while $t_{t}$ decreases as RI increases (so $t_{u}$ will also decrease); however, the volume of surplus water continues to increase but in a shorter fraction over time since the reduction in $T f d$ is larger than that in $t_{u}$ (Figure 9). The differences will decrease with RI due to the reduction in the tipping volume as suggested by Calder and Kidd [30]. Therefore, mechanical errors will increase, with surplus water following a polynomial rather than a linear trend, as in dynamic calibration.

Results from the semi-analytical models were similar to those of dynamic calibration in RC1; they differed mainly at RI $>700 \mathrm{~mm} \cdot \mathrm{h}^{-1}$, where their fitting values were smaller than those shown by the dynamic calibration. In RC2, semi-analytical models presented smaller values than those of dynamic calibration; they differed by more than $0.01 \mathrm{~mm}$ per tip at some RIs, although these differences were attenuated at low RI, where the simplified method linearized the surplus behavior maintaining the trend of the step data increment (Figure 10). 


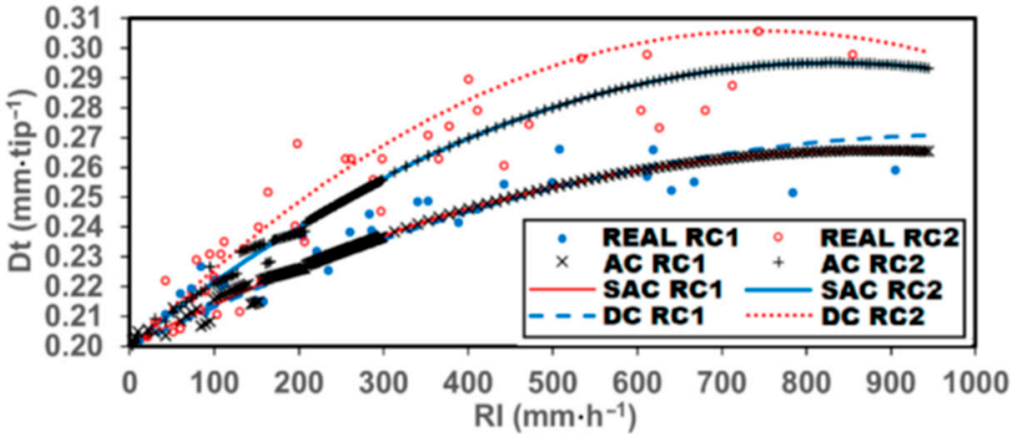

Figure 9. The relationship between the rainfall depth per tip and RI increment, obtained by the dynamic calibration method (DC), the semi-analytical calibration (AC), the simplified calibration (SAC) proposed methods, and reference values (REAL) in both RC1 and RC2.

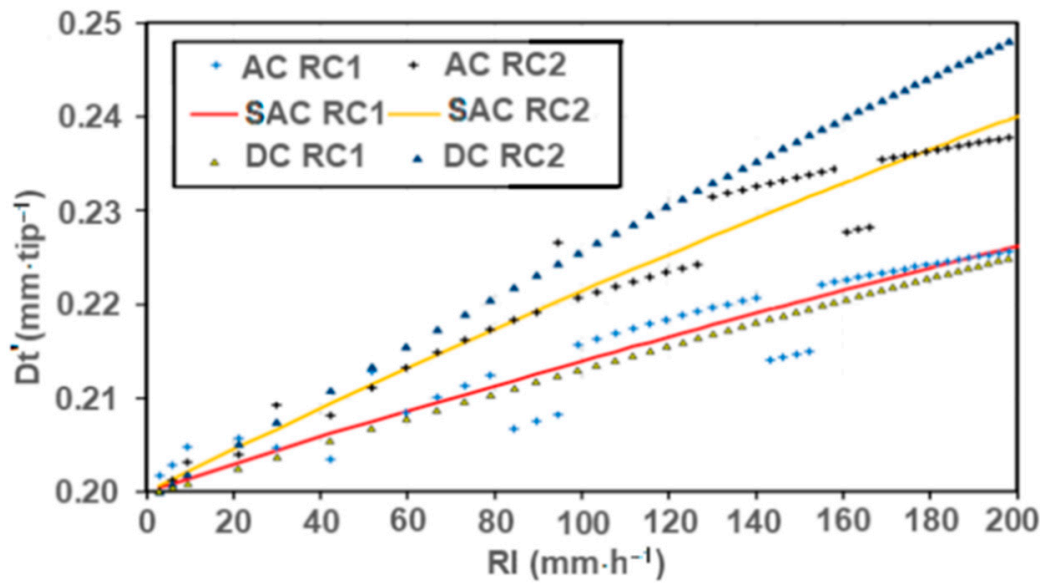

Figure 10. Rainfall depth increment per tip at RI below $200 \mathrm{~mm} \cdot \mathrm{h}^{-1}$, resulting from dynamic calibration (DC), semi-analytical calibration (AC), and simplified (SAC) proposed methods in both $\mathrm{RC} 1$ and RC2.

\subsection{Root Mean Square Error}

Looking at the RMSE analysis, for RC1 the dynamic calibration fitted best with real values in most of the intervals, and the simplified method better simulated the real values in RC2; however, the semi-analytical method had minor errors in the interval from 0 to $100 \mathrm{~mm} \cdot \mathrm{h}^{-1}$ in both TBRs, where most of the total precipitation is expected under real conditions (Table 1). Semi-analytical methods presented results that were similar to one another, but also to dynamic calibration results, especially in the first two intervals. On the other hand, the static calibration presented the highest RMSE values for all intervals.

Table 1. RMSE values (in percentage) for different RI intervals (in $\mathrm{mm} \cdot \mathrm{h}^{-1}$ ). The results with the lowest RMSE are in bold.

\begin{tabular}{ccccccccc}
\hline METHOD & \multicolumn{9}{c}{ RC1 } & \multicolumn{3}{c}{ RC2 } \\
\hline & $\mathbf{0 - 1 0 0}$ & $\mathbf{1 0 0 - 2 0 0}$ & $\mathbf{2 0 0 - 9 0 0}$ & $\mathbf{0 - 9 0 0}$ & $\mathbf{0 - 1 0 0}$ & $\mathbf{1 0 0 - 2 0 0}$ & $\mathbf{2 0 0 - 9 0 0}$ & $\mathbf{0 - 9 0 0}$ \\
\hline Simplified & 2.7 & 3.3 & 7.8 & 6.6 & 5.2 & $\mathbf{6 . 0}$ & $\mathbf{6 . 5}$ & $\mathbf{6 . 3}$ \\
S-analytical & $\mathbf{2 . 0}$ & 3.3 & 7.8 & 6.6 & $\mathbf{5 . 1}$ & 6.3 & 6.5 & 6.4 \\
Dynamic & 2.6 & $\mathbf{2 . 9}$ & $\mathbf{3 . 1}$ & $\mathbf{2 . 9}$ & 5.8 & 6.3 & 9.3 & 7.8 \\
Static & 4.8 & 6.2 & 13.2 & 10.9 & 9.4 & 14.5 & 38.0 & 28.0 \\
\hline
\end{tabular}

Semi-analytical methods and the dynamic calibration were able to reduce errors by more than 40 and 50\%, respectively, in contrast with the traditional static calibration suggested by the manufacturer in the two first studied intervals and even more than $70 \%$ in the 200 to $900 \mathrm{~mm} \cdot \mathrm{h}^{-1}$ interval. 


\subsection{Assessment of the Rainfall Measurement Errors in Venero Claro Mountain Basin}

According to the static calibration method, the annual average precipitation was Arromoro $1120.1 \mathrm{~mm}$; Collado Morales, $892.3 \mathrm{~mm}$; La Atalaya, $1143.4 \mathrm{~mm}$; La Dehesa, $517.7 \mathrm{~mm}$; Peña Parda, 910.7; $\mathrm{mm}$ and Trampalones, $993.4 \mathrm{~mm}$. Most of the precipitation occurred at RI $<10 \mathrm{~mm} \cdot \mathrm{h}^{-1}$; then, the percentage of rainfall within the RI intervals tended to decrease as RI increased except in the 150 to $200 \mathrm{~mm} \cdot \mathrm{h}^{-1}$ interval, where it increased (Table 2). This could be explained taking into account that even though the highest RIs were less frequent, their heavy rainfall resulted in high water accumulation in a short time; consequently, few high RI events could yield significant rainfall among them, which has a significant influence on measurement error, as suggested Molini et al. [50]

Table 2. Rainfall intensity data distribution in the Venero Claro mountain basin.

\begin{tabular}{ccccccc}
\hline $\begin{array}{c}\text { RI Intervals } \\
\left(\mathbf{m m} \cdot \mathbf{h}^{-\mathbf{1})}\right.\end{array}$ & Arromoro (\%) & $\begin{array}{c}\text { Collado } \\
\text { Morales (\%) }\end{array}$ & La Atalaya (\%) & La Dehesa (\%) & Peña Parda (\%) & $\begin{array}{c}\text { Trampalones } \\
\mathbf{( \% )}\end{array}$ \\
\hline $0-10$ & 64.64 & 53.75 & 63.89 & 67.14 & 67.18 & 32.90 \\
$10-20$ & 4.52 & 9.28 & 3.42 & 3.48 & 8.50 & 4.67 \\
$20-40$ & 1.68 & 6.70 & 2.62 & 3.32 & 6.57 & 6.83 \\
$40-60$ & 0.00 & 2.63 & 3.14 & 1.21 & 2.12 & 1.96 \\
$60-100$ & 1.44 & 1.87 & 4.68 & 0.00 & 1.18 & 9.24 \\
$100-150$ & 5.37 & 1.40 & 1.79 & 3.46 & 3.09 & 4.71 \\
$150-200$ & 0.00 & 0.00 & 3.93 & 15.74 & 10.50 & 22.69 \\
$>200$ & 21.84 & 24.36 & 16.54 & 15.74 & \\
\hline
\end{tabular}

At least $75 \%$ of the recorded rainfall on the basin was below $200 \mathrm{~mm} \cdot \mathrm{h}^{-1}$ and occurred within the droplet interval, and between 10 and $25 \%$ occurred at RI $>200 \mathrm{~mm} \cdot \mathrm{h}^{-1}$. Rainfall events above $200 \mathrm{~mm} \cdot \mathrm{h}^{-1}$ were more significant in Collado Morales, representing $25 \%$ of its recorded precipitation, and less frequent in Peña Parda and La Dehesa, representing $10.5 \%$ and $15.7 \%$, respectively.

The static calibration recommended by the manufacturer, in contrast with the other methodologies, generated an underestimation that varied among the monitored places. It reached an error of more than $6 \%$ (up to $701 \mathrm{~mm}$ or between 55 to $60 \mathrm{~mm}$ per year depending on the contrasted methodology) in Collado Morales (the area with the largest incidence of high RI) and about $1 \%$ (up to $51.8 \mathrm{~mm}$ or $5 \mathrm{~mm}$ per year) in La Dehesa (the zone with the lowest elevation and the least incidence of high RI; Table 3). However, for the total amount of data collected in the basin, a 2.05, 2.48, and 2.39\% error was observed with the dynamic, semi-analytic, and simplified methods, respectively, in contrast with the static calibration data.

Table 3. Total precipitation ( $\mathrm{mm}$ ) collected in each monitored zone during the study period and measurement error obtained according to different methodologies.

\begin{tabular}{|c|c|c|c|c|c|c|c|c|c|c|}
\hline \multirow{3}{*}{ ZONE } & \multicolumn{10}{|c|}{ CALIBRATION METHOD } \\
\hline & \multirow{2}{*}{ Static } & \multicolumn{3}{|c|}{ Dynamic } & \multicolumn{3}{|c|}{ Semi-Analytical } & \multicolumn{3}{|c|}{ Simplified } \\
\hline & & Total & $\mathrm{mm}$ & $\%$ & Total & $\mathrm{mm}$ & $\%$ & Total & $\mathrm{mm}$ & $\%$ \\
\hline Arromoro & $10,888.9$ & $11,126.3$ & 237.4 & 2.2 & $11,191.3$ & 302.4 & 2.8 & $11,177.8$ & 288.9 & 2.7 \\
\hline C. Morales & $10,432.3$ & $11,058.9$ & 626.6 & 6.0 & $11,133.3$ & 701.0 & 6.7 & $11,119.1$ & 686.8 & 6.6 \\
\hline La Dehesa & 5515.4 & 5541.6 & 26.2 & 0.5 & 5567.2 & 51.8 & 0.9 & 5558.3 & 42.9 & 0.8 \\
\hline Peña Parda & $12,869.8$ & $13,072.3$ & 202.5 & 1.6 & $13,117.7$ & 247.9 & 1.9 & $13,100.4$ & 230.6 & 1.8 \\
\hline La Atalaya & $14,412.2$ & $14,489.5$ & 77.3 & 0.5 & $14,561.7$ & 149.5 & 1.0 & $14,542.4$ & 130.2 & 0.9 \\
\hline Trampalones & 7840.8 & 8021.6 & 180.8 & 2.3 & 8077.0 & 236.2 & 3.0 & 8072.4 & 231.6 & 3.0 \\
\hline
\end{tabular}

The increase in the elevation across the basin and orientation affect the annual average rainfall and also appear to influence the incidence of very high RI events. The eastern and middle height location (Collado Morales) presented the largest underestimation; 
on the contrary, the western, lowest in altitude and flattest location (La Dehesa), the smallest (Figure 11).

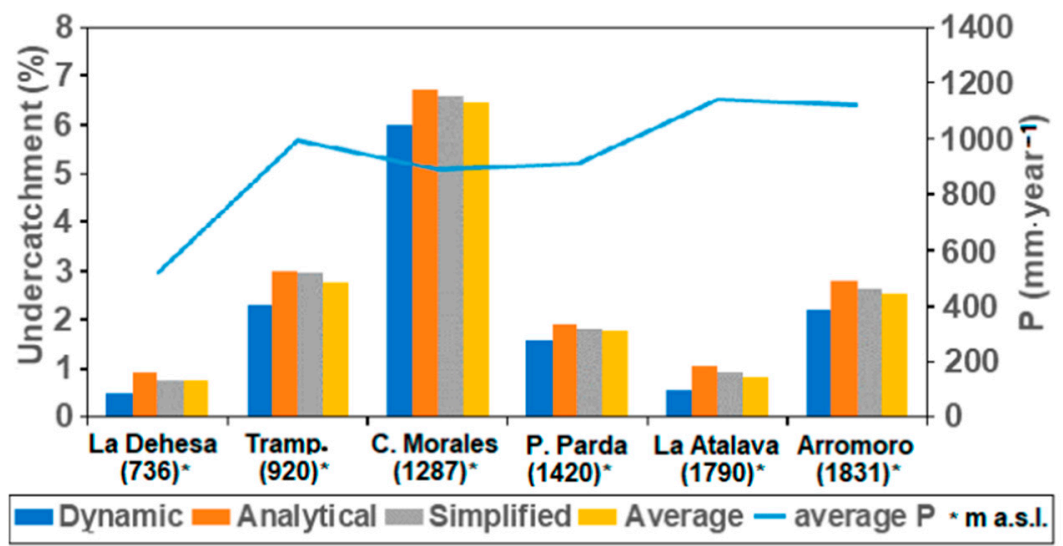

Figure 11. Underestimation percentage error for the Venero Claro mountain basin total recorded data, according to the dynamic, the semi-analytical, and the simplified calibration methods, contrasted with the static calibration traditionally employed in the basin. Further, the average between the tree method and the annual average precipitation within the monitored places is presented.

\section{Discussion}

This study has identified two main sources of surplus water during tipping movement, one caused by the time it takes the bucket to tip (St) since it cannot reposition itself fast enough, and some water is lost generating a surplus due to $t_{t}$ [17]; and the other generated by the critical drop $(S d)$, both related to RI variation, especially St. Among other variables, they depend on TBR characteristics described in this work, such as the size of the funnel orifice (this concerns the droplet size and its frequency) and the instrument resolution (the smaller the $V t$, the greater the effect of the same drop size in surplus) mentioned by Marsalek and Fankhauser [18,42]. Surplus due to droplet size has the potential to increase $S$, especially at RI, where there is no $S t$ (since $t_{t}$ is shorter than $t s$ ). However, once $S t$ appears, $S d$ can be considered negligible in contrast to $S t$.

Moreover, a random unexplained variation not related to RI, as a source or error, was also identified, which can be significant according to Ciach and Habib et al. [14,40] and can be observed at low RI where $t_{t}$ is expected to be constant. Since the $t_{t}$ variation at low RI is not attributed to the kinetic energy effect of falling drops during the tipping movement, it could be explained by other sources such as the buckets' self -functioning mechanism, drag variations, friction force variation in the fixed axis throughout the experiment, variability in $D$ size, experimental error during calibration, changes in falling water direction, levelled errors, an incomplete evacuation of water from the tipping bucket or funnel as Sypka [35] suggested, the buckets' volume variation, water origin, initial conditions of the buckets, wind effects during tests [18,37], among others. However, since this random error seems to be unrelated to RI, it cannot be avoided by the proposed calibration methods. Nevertheless, as Fankhauser [42] affirmed, this random error was small compared to the ones derived from RI or others that were not studied in this work such as wind.

The frame-by-frame analysis of the slow-motion videos let us observe an effect due to the drop size before $D$, whose impact on the bucket generated slight oscillations of the tipping mechanism changing $h_{t}$ and adding resistance to the bucket falling movement. After a slight oscillation, the bucket tries to return to its initial position, generating an opposite force to that developed by the $D$ impact. Consequently, the $t_{t}$ unexplained variation could be also attributed to this effect.

The study's methods have shown the same polynomial trend in the evolution of the calibration curve due to the increment in $S$ but also to the compensatory effect as RI increases. However, it could also fit a linear regression for a lower RI interval as Humphrey et al. [17] suggested, since the curve accentuates as RI increases. Luyckx and 
Berlamont [32] defined three regions in the calibration curve: the first was horizontal and corresponded to very low RI where $t_{t}<T f d$ (no drops fall into the bucket). The second comprised the region where the buckets are filled with drops but $t_{t}>\mathrm{Tfd}$ and some water gets lost. The third region corresponded to high RI (where water falls as a continuous trickle), $t_{t}$ decreases and compensates water losses approaching a nearly horizontal line. These three regions have been also observed in this study.

The first corresponds to low RI, less than 40 and $20 \mathrm{~mm} \cdot \mathrm{h}^{-1}$ in RC1 and RC2, respectively, where $t_{t}<t s$, (no $\left.S t\right)$; consequently, no extra drops after $D$ fall into the bucket during the tipping movement. Nevertheless, the region shows $S d$ and random unexplained errors, which can generate an overestimation instead of an underestimation, as was observed by Hoffmann, Marsalek, and Shedekar et al. [18,22,33].

The second region refers to RI where $t_{t}$ is larger than $t s$ and some water falls as surplus into the bucket during the tipping movement; likewise, in this region $S$ would increase due to $S t$ and $S d$ in a stepwise trend, so underestimation would be more noticeable than in the first region. The second region ends at about $200 \mathrm{~mm} \cdot \mathrm{h}^{-1}$ in the studied TBRs once the falling water becomes a constant trickle.

The third region is above $200 \mathrm{~mm} \cdot \mathrm{h}^{-1}$, where the kinematic energy contributed by the falling water to the bucket balance is constant, generating a continuous increase in $S$ caused by $S t$ ( $S d$ does not exist). The kinematic energy increases and accelerates the tipping movement but also reduces the moment of inertia reducing $V t$, resulting in a compensatory effect as RI values increase, causing a parabolic trend in the curve.

The amplitude of each region will depend on the rain gauge characteristics and thus, it will change from one TBR to another. However, the Luyckx and Berlamont [32] assumption of nearly horizontal lines in the first and third regions is questionable since the bucket volume compensatory effect must be almost equal to $S$ during a certain time to become horizontal, but it can be possible depending on TBR characteristics and on the funnel storage. This horizontal assumption could have made Vasvári [37] not recognize the three regions.

The total error obtained by the tested calibration methods varied from $2 \%$ to $28 \%$, depending on RI, since data errors are smaller as RI decreases [17-19,45]; similar values can be observed in literature: a 2 to $16 \%$ in a shorter interval reported by Niemczynowicz [29], from 5 to $29 \%$ as reported by Humphrey et al. [17], the 5.2, 11.4, 17.7, 25.8, and $37.7 \%$ depending on RI reported by Sypka [35], or even the $10 \%$ underestimation between a 25 to $400 \mathrm{~mm} \cdot \mathrm{h}^{-1}$ interval reported by Marsalek [18].

The errors obtained by the dynamic and semi-analytical calibration methods (around $2 \%$ in RC1 and $5 \%$ in RC2) at RI below $100 \mathrm{~mm} \cdot \mathrm{h}^{-1}$ were smaller, by more than $50 \%$, than those reported by the manufacturer (5\%) for RC1, but also than the 5 and $9 \%$ obtained by a static calibration. Thus, a proper calibration can significantly improve data quality in TBR measurements. However, calibration success is based both on the accuracy of requested parameters, depending on a correct previous static calibration [34], and an adequate levelled platform installation. Since the study used two different TBR models, the error could not be the same if the same procedure is applied to a more robust TBR model. As WMO [19] says, the "characteristics and calibration of TBRs are a complex interaction of many variables and can vary from station to station".

In the study case of Venero Claro, the maximum reduction in error exceeded $6 \%$, considering the data from the monitored zone and $2.48 \%$ for data from the whole basin. These may be more significant with real-time RI measurements or in a shorter data acquisition frequency since the RI calculated at a 30-min resolution could not represent the RI experienced by the gauge over that time $[14,35,43,51]$ or in isolated high RI events such as those used for statistical data analysis to calculate return periods [52], flood prevention, and the design of projects. However, the 30-min resolution in data acquisition highlights the capacity of the method to reduce errors in measurements under field conditions. Therefore, a very fine resolution of RI data is recommended to correct the measurement error (1-min 
resolution is recommended by the UNE EN 17277:2021). However, it is not always possible to achieve since most of the historical rainfall data were logged over a greater frequency.

Rainstorms in the basin enter predominantly through the West and Southwest [49] and hit the western slopes and eastern mountain summits; consequently, these areas presented a higher underestimation error. A windward effect was observed in the eastern areas Collado Morales and Arromoro, where a larger number of high RI events occurs. These events were less frequent in the western areas (Peña Parda and La Dehesa). Since RI storms usually cover a small area, they can be blocked by orography in Collado Morales and Arromoro, originating in a type of rain shadow for high RI events. Therefore, the altitude, the topography, and location in a basin can create an environment favorable to high RI storms and thus, the mounting site of the TBR network can have significant effects on measurement errors.

The results highlight the benefits of calibration for reliable rainfall monitoring based on traditional gauges and we agree with LaBarbera [43]: "Calibration should be considered by weather service agencies and technicians working with TBRs to guarantee more accuracy on the measurements in the future". Proper equipment handling together with rigorous calibration for data correction is essential but commonly neglected in the management of many operational monitoring networks; fortunately, some new TBR models include an internal intensity correction to compensate for kinematic effects at higher intensities [53]. The studies of Habib et al., La Barbera et al., and Molini et al. $[4,43,45,50]$ have shown that measurement errors significantly amplify the final error in the derived statistics for rainfall extremes, essential for different applications such as flow early warning systems [7]. Therefore, proper calibration is essential in climate and hydrological management and forecasting, but it is not always done.

The semi-analytical calibration methods presented not only the same trend but also similar error reductions to those of dynamic calibration, a methodology widely discussed, recommended, and well-known in the scientific community [10,17,22,37,39,42], obtaining even better results in the interval from 0 to $100 \mathrm{~mm} \cdot \mathrm{h}^{-1}$, the interval where most of the precipitation occurs, which means that the proposed semi-analytical method and its simplified version are efficient methods for reduction in TBR error measurements. Nevertheless, the proposed semi-analytical methodologies do not eliminate data measurement errors, even if the estimation and measurement of the calibration parameters are improved $\left(t_{t}, A\right.$, $\Omega, h, h_{b}, h_{t}, l$, and $V d$ ) due to different factors such as a random unexplained variation that is characteristic of the tipping mechanism, and they do not consider other sources of variation, such as wind, since they are based on the semi-analytical interpretation of the surplus water effect during the tipping movement, but as Shedekar et al., Shimizu et al. and Sypka [33-35] mentioned, errors can be reduced by proper calibration and thus, so can their effect on data.

\section{Conclusions}

There are two main sources of surplus water, one caused by the time the bucket takes to tip $(S t)$ and the other generated by the critical drop $(S d)$; both depend on RI, although the $S t$ effect is the most significant. Moreover, there is a random unexplained variation in $t_{t}$ (not related to RI). Measurement errors increase as RI increases so data error can significantly increase at high RI events. Therefore, measurement errors would be higher in isolated high RI storms, which are frequently used for the analysis of statistical data; thus, a very fine resolution of RI data would be recommended. Further, the combination of altitude, topography, and location in a basin can create an environment favorable to high RI storms, so the mounting site of a TBR can have a significant effect on measurement errors.

Calibration studied methods can reduce TBR measurement error; however, they cannot be totally eliminated, even when the estimation and measurement of the calibration parameters are improved since random unexplained variation is implicit in the tipping mechanism and some sources of error such wind are not considered. Nevertheless, proper 
calibration can drastically reduce rain data error, by more than $50 \%$ in relation to the values obtained only by the static calibration recommended by the manufacturers.

Calibration curves show three regions regarding water behavior in the tipping mechanism. The first shows a very low RI, where $t_{t}<T f d$ and there is no St; errors in this region are due to $S d$ and random unexplained variations. The second corresponds to RI, where $t_{t}>T f d$ and some water falls as surplus into the bucket during tipping movement as drops, meaning that $S$ would increase due to $S t$ and $S d$ in an attenuated stepwise trend and underestimation would be more noticeable. The third region starts once the falling water becomes a constant trickle and its kinematic energy influence on the bucket balance is constant; thus, it generates a constant increase in $S$ (caused by $S t$ ), but also a constant reduction of $t_{t}$ and $V t$, which results in a compensatory effect and a curved $D t^{\prime}$ increment as RI increases.

The semi-analytical calibration methods proposed in this work (Equations (8) and (10)) have proved to be effective alternative methods for TBR calibration, obtaining even better results than the well-known, recently standardized dynamic calibration at the most frequent RI, especially the semi-analytical method, which requires more experimental procedures than its simplified version, which is easier and faster to perform. However, we cannot say that the proposed methods are faster or easier to perform than dynamic calibration, but they do open the door to a better understanding of the mechanical biases in TBRs for future calibration methods and for gauging manufacture structure design, presenting an efficient alternative methodology for calibration from a different point of view than that of traditional calibration methods. It is also suitable for automation and real-time data correction.

\section{Patents}

A patent application was presented in the Spanish Patent Office: No. P202030968.

Author Contributions: Conceptualization, D.A.S.-C., S.Z. and L.R.-S.; methodology, D.A.S.-C. and F.C.-I.; software, D.A.S.-C.; validation, A.D.-H., D.A.S.-C. and S.Z.; formal analysis, F.C.-I. and D.A.S.-C.; investigation, D.A.S.-C., F.C.-I. and S.Z.; resources, L.R.-S. and A.D.-H.; data curation, D.A.S.-C., A.D.-H. and L.R.-S.; writing-original draft preparation, D.A.S.-C. and L.R.-S.; writingreview and editing, D.A.S.-C. and A.D.-H.; visualization, D.A.S.-C., F.C.-I. and S.Z.; supervision, A.D.-H.; project administration, L.R.-S.; funding acquisition, A.D.-H. All authors have read and agreed to the published version of the manuscript.

Funding: This research received no external funding.

Institutional Review Board Statement: Not applicable.

Informed Consent Statement: Not applicable.

Data Availability Statement: The authors were unable to find a valid data repository for the data used in this study. These data are available upon request from Geological Hazards Division, Instituto Geológico y Minero de España (IGME-CSIC), email: andres.diez@igme.es at Geological Survey of Spain.

Acknowledgments: The authors wish to thank the SMART-HYDRO project (PCD1820280276), the DRAINAGE-3-R project (CGL2017-83546-C3-3-R AEI/FEDER, UE) and the UPM Programa Propio for their support of this study. Without their collaboration, the work would have not been completed.

Conflicts of Interest: The authors declare no conflict of interest.

\section{References}

1. Kim, J.; Han, H. Evaluation of the CMORPH high-resolution precipitation product for hydrological applications over South Korea. Atmos. Res. 2021, 258, 105650. [CrossRef]

2. Biswas, A.K. History of Hydrology; Elsevier Science Limited: Amsterdam, The Netherlands, 1970.

3. Gnecco, I.; Palla, A.; La Barbera, P. A dimensionless approach for the runoff peak assessment: Effects of the rainfall event structure. Hydrol. Earth Syst. Sci. 2018, 22, 943-956. [CrossRef] 
4. Habib, E.H.; Meselhe, E.A.; Aduvala, A. V Effect of local errors of tipping-bucket rain gauges on rainfall-runoff simulations. J. Hydrol. Eng. 2008, 13, 488-496. [CrossRef]

5. Villarini, G.; Mandapaka, P.V.; Krajewski, W.F.; Moore, R.J. Rainfall and sampling uncertainties: A rain gauge perspective. J. Geophys. Res. Atmos. 2008, 113, 1-12. [CrossRef]

6. Agarwal, A.; Mishra, S.K.; Ram, S.; Singh, J.K. Simulation of Runoff and Sediment Yield using Artificial Neural Networks. Biosyst. Eng. 2006, 94, 597-613. [CrossRef]

7. Pasculli, A.; Cinosi, J.; Turconi, L.; Sciarra, N. Learning case study of a shallow-water model to assess an early-warning system for fast alpine muddy-debris-flow. Water 2021, 13, 750, ISBN 3908713556159. [CrossRef]

8. Bowman, K.P. Comparison of TRMM precipitation retrievals with rain gauge data from ocean buoys. J. Clim. 2005, 18, 178-190. [CrossRef]

9. Tapiador, F.J.; Navarro, A.; García-Ortega, E.; Merino, A.; Sánchez, J.L.; Marcos, C.; Kummerow, C. The Contribution of Rain Gauges in the Calibration of the IMERG Product: Results from the First Validation over Spain. J. Hydrometeorol. 2020, 21, 161-182. [CrossRef]

10. Borup, M.; Grum, M.; Linde, J.J.; Mikkelsen, P.S. Dynamic gauge adjustment of high-resolution X-band radar data for convective rain storms: Model-based evaluation against measured combined sewer overflow. J. Hydrol. 2016, 539, 687-699. [CrossRef]

11. Ochoa-Rodriguez, S.; Wang, L.P.; Willems, P.; Onof, C. A Review of Radar-Rain Gauge Data Merging Methods and Their Potential for Urban Hydrological Applications. Water Resour. Res. 2019, 55, 6356-6391. [CrossRef]

12. Todini, E. A Bayesian technique for conditioning radar precipitation estimates to rain-gauge measurements. Hydrol. Earth Syst. Sci. 2001, 5, 187-199. [CrossRef]

13. Tokay, A.; Bashor, P.G.; McDowell, V.L. Comparison of rain gauge measurements in the mid-atlantic region. J. Hydrometeorol. 2010, 11, 553-565. [CrossRef]

14. Habib, E.; Krajewski, W.F.; Kruger, A. Sampling errors of tipping-bucket rain gauge measurements. J. Hydrol. Eng. 2001, 6, 159-166. [CrossRef]

15. Sexton, A.M.; Sadeghi, A.M.; Zhang, X.; Srinivasan, R.; Shirmohammadi, A. Using NEXRAD and rain gauge precipitation data for hydrologic calibration of SWAT in a northeastern watershed. Trans. ASABE 2010, 53, 1501-1510. [CrossRef]

16. Sun, X.; Mein, R.G.; Keenan, T.D.; Elliott, J.F. Flood estimation using radar and raingauge data. J. Hydrol. 2000, 239, 4-18. [CrossRef]

17. Humphrey, M.D.; Istok, J.D.; Lee, J.Y.; Hevesi, J.A.; Flint, A.L. A New Method for Automated Dynamic Calibration of TippingBucket Rain Gauges. J. Atmos. Ocean. Technol. 1997, 14, 1513-1519. [CrossRef]

18. Marsalek, J. Calibration of the tipping-bucket raingage. J. Hydrol. 1981, 53, 343-354. [CrossRef]

19. WMO. Guide to Meteorological Instruments and Methods of Observation (WMO-No. 8); World Meteorological Organization: Geneva, Switzerland, 2008.

20. Cauteruccio, A.; Colli, M.; Freda, A.; Stagnaro, M.; Lanza, L.G. The role of free-stream turbulence in attenuating the wind updraft above the collector of precipitation gauges. J. Atmos. Ocean. Technol. 2020, 37, 103-113. [CrossRef]

21. Duchon, C.E.; Biddle, C.J. Undercatch of tipping-bucket gauges in high rain rate events. Adv. Geosci. 2010, 25, 11-15. [CrossRef]

22. Hoffmann, M.; Schwartengräber, R.; Wessolek, G.; Peters, A. Comparison of simple rain gauge measurements with precision lysimeter data. Atmos. Res. 2016, 174-175, 120-123. [CrossRef]

23. Michelson, D.B. Systematic correction of precipitation gauge observations using analyzed meteorological variables. J. Hydrol. 2004, 290, 161-177. [CrossRef]

24. Sevruk, B.; Ondrás, M.; Chvíla, B. The WMO precipitation measurement intercomparisons. Atmos. Res. 2009, 92, 376-380. [CrossRef]

25. Molini, A.; La Barbera, P.; Lanza, L.G.; Stagi, L. Rainfall intermittency and the sampling error of tipping-bucket rain gauges. Phys. Chem. Earth Part C Solar Terr. Planet. Sci. 2001, 26, 737-742. [CrossRef]

26. Ren, Z.; Li, M. Errors and correction of precipitation measurements in China. Adv. Atmos. Sci. 2007, 24, 449-458. [CrossRef]

27. Duchon, C.E.; Essenberg, G.R. Comparative rainfall observations from pit and aboveground rain gauges with and without wind shields. Water Resour. Res. 2001, 37, 3253-3263. [CrossRef]

28. Simić, M.M. Effect of the siphon control on the dynamic characteristics of a tipping bucket raingauge. Hydrol. Sci. J. 1994, 39, 35-46. [CrossRef]

29. Niemczynowicz, J. The Dynamic Calibration of Tipping-Bucket Raingauges. Hydrol. Res. 1986, 17, 203-214. [CrossRef]

30. Calder, I.R.; Kidd, C.H.R. A note on the dynamic calibration of tipping-bucket gauges. J. Hydrol. 1978, 39, 383-386. [CrossRef]

31. Costello, T.A.; Williams, H.J. Short duration rainfall intensity measured using calibrated time-of-tip data from a tipping bucket raingage. Agric. For. Meteorol. 1991, 57, 144-155. [CrossRef]

32. Luyckx, G.; Berlamont, J. Simplified method to correct rainfall measurements from tipping bucket rain gauges. Urban Drain. Model. 2001, 767-776. [CrossRef]

33. Shedekar, V.S.; King, K.W.; Fausey, N.R.; Soboyejo, A.B.O.; Harmel, R.D.; Brown, L.C. Assessment of measurement errors and dynamic calibration methods for three different tipping bucket rain gauges. Atmos. Res. 2016, 178-179, 445-458. [CrossRef]

34. Shimizu, T.; Kobayashi, M.; Iida, S.; Levia, D.F. A generalized correction equation for large tipping-bucket flow meters for use in hydrological applications. J. Hydrol. 2018, 563, 1051-1056. [CrossRef] 
35. Sypka, P. Dynamic real-time volumetric correction for tipping-bucket rain gauges. Agric. For. Meteorol. 2019, 271, 158-167. [CrossRef]

36. Kohfahl, C.; Saaltink, M.W. Comparing precision lysimeter rainfall measurements against rain gauges in a coastal dune belt, Spain. J. Hydrol. 2020, 591, 125580. [CrossRef]

37. Vasvári, V. Calibration of tipping bucket rain gauges in the Graz urban research area. Atmos. Res. 2005, 77, 18-28. [CrossRef]

38. Wang, J.; Fisher, B.L.; Wolff, D.B. Estimating rain rates from tipping-bucket rain gauge measurements. J. Atmos. Ocean. Technol. 2008, 25, 43-56. [CrossRef]

39. Bergmann, H.; Breinhälter, H.; Hable, O.; Krainer, R. Calibration of tipping bucket hyetographs. Phys. Chem. Earth, Part C Solar, Terr. Planet. Sci. 2001, 26, 731-736. [CrossRef]

40. Ciach, G.J. Local random errors in tipping-bucket rain gauge measurements. J. Atmos. Ocean. Technol. 2003, 20, 752-759. [CrossRef]

41. Colli, M.; Lanza, L.G.; La Barbera, P.; Chan, P.W. Measurement accuracy of weighing and tipping-bucket rainfall intensity gauges under dynamic laboratory testing. Atmos. Res. 2014, 144, 186-194. [CrossRef]

42. Fankhauser, R. Measurement properties of tipping bucket rain gauges and their influence on urban runoff simulation. Water Sci. Technol. 1997, 36, 7-12. [CrossRef]

43. La Barbera, P.; Lanza, L.G.; Stagi, L. Tipping bucket mechanical errors and their influence on rainfall statistics and extremes. Water Sci. Technol. 2002, 45, 1-9. [CrossRef]

44. Liao, M.; Liao, A.; Liu, J.; Cai, Z.; Liu, H.; Ma, T. A novel method and system for the fast calibration of tipping bucket rain gauges J. Hydrol. 2020, 125782. [CrossRef]

45. Molini, A.; Lanza, L.G.; La Barbera, P. Improving the accuracy of tipping-bucket rain records using disaggregation techniques. Atmos. Res. 2005, 77, 203-217. [CrossRef]

46. Song, Y.; Han, D.; Rico-Ramirez, M.A. High Temporal Resolution Rainfall Information Retrieval from Tipping-Bucket Rain Gauge Measurements. Procedia Eng. 2016, 154, 1193-1200. [CrossRef]

47. Davis Instruments Corp. Rain Collector 7852. Available online: www.davisinstruments.com/product_documents/weather/ manuals/07395-334_IM_7852.pdf (accessed on 16 June 2021).

48. Davis Instruments Corp. Installation Manual: Rain Collector II. Available online: www.davisnet.com/product_documents/ weather/manuals/07395-224_IM_7852.pdf (accessed on 16 June 2021).

49. Ruiz-Villanueva, V.; Bodoque, J.M.; Díez-Herrero, A.; Eguibar, M.A.; Pardo-Igúzquiza, E. Reconstruction of a flash flood with large wood transport and its influence on hazard patterns in an ungauged mountain basin. Hydrol. Process. 2013, 27, 3424-3437. [CrossRef]

50. Molini, A.; Lanza, L.G.; La Barbera, P. The impact of tipping-bucket raingauge measurement errors on design rainfall for urban-scale applications. Hydrol. Process. 2005, 19, 1073-1088. [CrossRef]

51. Muñoz, P.; Célleri, R.; Feyen, J. Effect of the resolution of tipping-bucket rain gauge and calculation method on rainfall intensities in an andean mountain gradient. Water 2016, 8, 534. [CrossRef]

52. Marra, F.; Borga, M.; Morin, E. A Unified Framework for Extreme Subdaily Precipitation Frequency Analyses Based on Ordinary Events. Geophys. Res. Lett. 2020, 47, e2020GL091498. [CrossRef]

53. Kochendorfer, J.; Earle, M.E.; Hodyss, D.; Reverdin, A.; Roulet, Y.A.; Nitu, R.; Rasmussen, R.; Landolt, S.; Buisán, S.; Laine, T. Undercatch adjustments for tipping-bucket gauge measurements of solid precipitation. J. Hydrometeorol. 2020, 21, 1193-1205. [CrossRef] 